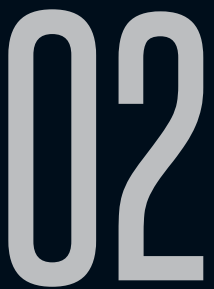

\title{
DEU IMPRINTING!': VAMPIROS, LITERATURA BEST-SELLER E CONVERGÊNCIA DAS MÍDIAS A PARTIR DO FENÔMENO JUVENIL THE TWILIGHT SAGA
}

Jennifer da Silva Gramiani Celeste (UFJF) Juliana Gervason Defilippo (CES/JF)

Recebido em 13 mar 2019. Jennifer da Silva Gramiani Celeste é Doutoranda em Aprovado em 08 mai 2019. Letras (Estudos Literários) pela Universidade Federal de Juiz de Fora (UFJF). É atuante no que se refere às interfaces dialógicas entre Literatura e Internet, ademais, Cultura da Convergência, Cultura de Massa, Educação na Cibercultura e Adolescência. É Membro Pesquisadora do Grupo de Pesquisa "A Literatura e os Cibercaminhos", sediado pelo Programa de Mestrado em Letras (Literatura Brasileira), pertencente ao Centro de Ensino Superior de Juiz de Fora. Lattes: http://lattes.cnpq.br/3592548159560060 Blog: http:// entrelinhasentrepautas.blogspot.com.br

Juliana Gervason Defilippo é Pós-Doutoranda em Literatura, Cultura e Contemporaneidade pela Pontifícia Universidade Católica do Rio de Janeiro (PUC-RJ). É Professora e Coordenadora Adjunta do Programa de Mestrado em Letras (Literatura Brasileira) do Centro de Ensino Superior de Juiz de Fora (CES/JF), bem como também Editora-Gerente da CES

1 No universo de Twilight, o termo Imprinting se refere a uma espécie de forte conexão a qual comumente ocorre entre seres sobrenaturais - tais como vampiros e lobisomens - e seres humanos. 
Revista (ISSN 1983-1625 - Qualis B1 e outros estratos). Possui experiência na área de Letras, atuando com os cotejos transdisciplinares viabilizados pelos Estudos Literários, com destaque para as interfaces dialógicas entre Literatura e Internet, Literatura e Diversidade e Literatura Feminina. É Líder do Grupo de Pesquisa "A Literatura e os Cibercaminhos", sediado pelo Programa de Mestrado em Letras (Literatura Brasileira), pertencente ao CES/JF. Lattes: http:// lattes.cnpq.br/2636818119719002

Resumo: The Twilight Saga, nacionalmente conhecida como A Saga Crepúsculo, idealizada pela escritora norte-americana Stephanie Mayer, mobilizou a indústria literária e do entretenimento em meados do ano de 2008, quando lançada no Brasil. Entre seres humanos, vampiros e lobisomens, Twilight impactara a Literatura Juvenil, assim como conduzira a imersão de jovens no universo literário, estes, até então pouco adeptos e cativos às práticas de leitura. Defronte a este contexto, o presente artigo objetiva dissertar e refletir acerca da dinâmica de produção literária dedicada aos jovens a partir do fenômeno da coleção Crepúsculo (2008), considerando, para tanto, a abordagem de temas sobrenaturais na Literatura em meio ao sistema cultural de convergência das mídias. Palavras-chave: Literatura Juvenil; Convergência das Mídias; The Twilight Saga.

Abstract: The Twilight Saga, nationally know as A Saga Crepúsculo, created by north-american writer Stephanie Mayer, mobilited the literary's and entertainment's industries in 2008's years, when launched in Brazil. Among humans, vampires and werewolfs, Twilight impacted the Juvenile Literature, as well as led to immersion of youngs on literary universe, until then little adepts and captives at reading practices. In this context, the present article aims to discuss and reflect on the dynamics of literary production dedicated to young people from de phenomenon of 
the Twilight Saga, considering, therefore, the approach of supernatural themes in Literature in the cultural system of media's convergence.

Keywords: Juvenile Literature; Convergence of Media; The Twilight Saga.

\section{INTRODUÇÃO}

The Twilight Saga, a série vampiresca escrita por Stephanie Mayer, tornou-se um ícone literário de uma geração e transgressor de balizas impostas à Literatura Juvenil, tal como outrora fora considerada a mágica trajetória do jovem bruxo Harry Potter. Os livros impactaram a vida de adolescentes pouco cativos às práticas de leitura, tendo sido traduzidos no Brasil pela editora Intrínseca no ano de 2008 sob o título de Crepúsculo.

Mesmo após dez anos desde a primeira publicação de Crepúsculo (2008) no Brasil, ainda é possível verificarmos os vestígios do legado da história de romance e guerra entre vampiros, lobisomens e seres humanos, especialmente no que concerne à inserção de jovens no âmbito literário, assim como ao processo de formação destes indivíduos enquanto leitores, ou ainda, ao aquecimento do mercado de consumo e das comunicações, haja vista a idealização de produtos, demais coleções literárias, filmes e seriados televisivos cujos pilares se instituíram com base na apresentação de temas congêneres. Das páginas dos livros impressos às telas dos cinemas, televisores e dispositivos de natureza eletrônica, as personagens e o enredo de Twilight fazem-se presentes e se renovam a cada acesso, visualização, curtida ou compartilhamento na grande rede de computadores, confirmando as viabilidades de ser e estar jovem, leitor e, também, nativo e conivente à era digital. 
Ao vislumbrarmos este panorama, no presente artigo nos propomos a suscitar algumas reflexões acerca do alcance desta franquia literária no que se refere à abordagem de temáticas sobrenaturais na Literatura produzida em contexto de convergência midiática.

\section{O VAMPIRESCO E O SOBRENATURAL NA LITERATURA BEST-SELLER}

Afinal, o que há por detrás do fenômeno Twilight? Esta e outras tantas indagações de semelhante natureza pairam sobre a atmosfera sobrenatural a qual acolheu milhares de jovens de diferentes nacionalidades, sedentos não por sangue, tal como comumente o fazem os vampiros, mas sim por títulos literários a eles exclusivamente dedicados. O sucesso alcançado por esta franquia literária indubitavelmente se figura como fator de primordial análise para que possamos nos tornar capacitados a compreender e a debater seu poder sobre a produção literária juvenil na contemporaneidade digital.

O estudioso Franco Moretti é aquele quem nos auxilia quando na obra de sua autoria, intitulada A literatura vista de longe (2008), discorre a respeito do elemento denominado pattern ${ }^{2}$. Segundo Moretti (2008), evento, ciclo e longa duração são reconhecidamente dimensões temporais as quais obtiveram distintas sortes no âmbito da história da Literatura. Ainda que questões atreladas aos eventos e à longa duração tenham sido exploradas adequadamente no meio acadêmico, "[...] o tempo do ciclo, permaneceu, ao contrário, em boa medida inexplorado [...]" (MORETTI, 2008, p.31). Algo interessante, já que é por intermédio deste que podemos melhor desbravar circunstâncias de produções literárias similares a 
Crepúsculo (2008) e a outros demais títulos. Moretti (2008), porém, justifica-se, salientando que a crítica literária até então não havia sido capaz de imergir na especificidade característica dos ciclos, pois estes "[...] constituem estruturas temporárias internas ao fluxo contínuo da história [...]" (2008, p.31 - grifo do autor).

Os ciclos os quais se desenvolvem nos meandros da Literatura, conforme assim nos apresenta Moretti (2008, p.34), são estruturas que comportam repetições e, portanto, peculiaridades como regularidade, ordem e forma. Deste modo, torna-se facilmente compreensível o motivo pelo qual acontecera o expressivo lançamento de livros, paralelo aos volumes da saga Crepúsculo (2008), os quais também contemplavam enredos e personagens comuns ao universo dos vampiros. Tendo em vista o sucesso alcançado por Twilight, somos capazes de supor que livros sobre a classe de vampiros, engavetados por distintas e desconhecidas razões, puderam vir à tona e aproveitar a circunstância de boa crítica e recepção quanto à abordagem deste tema na Literatura - e, por óbvio, aqui citamos a favorável dinâmica do mercado literário impresso vigente à época. llustrativamente, podemos mencionar a série Academia de vampiros (Agir, 2007), produzida por Richelle Mead; o livro Morto até o anoitecer (Ediouro, 2009), de Charlaine Harris, aclamado por dar origem ao célebre seriado televisivo True Blood; a saga House of night (Novo Século, 2007), da autoria de P. C. Cast; e, por fim, os volumes pertencentes à série teen feminina intitulada Insaciável (Record, 2011), idealizada pela escritora Meg Cabot ${ }^{3}$.

São temporários os ciclos, pois seus cursos são breves ou podem se estender por dez, vinte ou até mesmo cinquenta anos,

3 Destacamos novamente que a obra de Stephanie Mayer originalmente fora publicada no ano de 2005. 
nos aponta Moretti (2008, p.31). De fato, transcorridos um ou dois anos após a publicação do primeiro volume de Twilight, o frenesi observado em torno da Literatura de cunho vampiresco, cessara. Entretanto, é preciso reconhecermos: a abordagem sobrenatural se constituíra algo de tamanha grandiosidade, tanto que, até os dias atuais, escrever sobre vampiros ou lobisomens personagens também presentes na obra de Mayer - ainda está em alta $^{4}$. Um exemplo é a existência de searas específicas a este tipo de Literatura em redes de interação social voltadas à publicação literária no ambiente eletrônico, como Wattpad ${ }^{5}$. Parcialmente, também podemos atribuir este fato à possibilidade de manifestação literária no ciberespaço por meio da escrita de fanfics, claramente impulsionada pelo intricado sistema cultural e participativo de fãs.

Para além deste cenário, citamos alguns livros lançados após o fenômeno Twilight, os quais também contemplam narrativas de cunho sobrenatural, como é o caso dos títulos literários A maldição do tigre (Arqueiro, 2011), de Colleen Houck; Sangue quente (Leya, 2012), de Isaac Marion - inclusive adaptado para as telas do cinema no ano de 2013, sob o título Meu Namorado é um Zumbi, sucesso entre os adolescentes; e Os instrumentos mortais (Record, 2013), de Cassandra Claire. Na mídia televisiva, a produção de séries teen sobrenaturais também passara a se fazer demasiada frequente. Em relação a este fato, citamos Teen Wolf, The Secret Circle, Shadowhunters, True Blood e The Vampire Diaries.

4 Para além da exemplificação a qual apresentamos a seguir no texto, também podemos mencionar a editora brasileira Dark Side, hoje tida como uma das principais responsáveis pela popularização de títulos literários, entre estrangeiros e nacionais, tocantes ao terror e ao suspense.

5 A exemplo disto, recomendamos o acesso ao seguinte link: https://www.wattpad. com/stories/vampiros Acesso em 15.Mar.2019. 
Aliás, na década de 1990, o seriado Buffy, The Vampire Slayer ${ }^{6}$ - símbolo da cultura pop norte-americana -, apresentava-nos uma protagonista bastante atuante, de forma ainda isolada e sob atmosfera ímpar, combatendo vampiros, demônios e demais forças advindas das trevas. O êxito alcançado por esta produção levara uma de suas principais personagens, Angel, a ganhar seu próprio spin-off. É caro também nos lembrarmos que Buffy e Angel protagonizam um romance épico e proibido por se tratarem de uma humana e um vampiro - acontecimento este que nos alude à história apresentada por Mayer em Twilight.

Averiguamos que ainda que Crepúsculo (2008) tenha sido absolutamente responsável pelo renascimento desta temática na Literatura - e aqui nos referimos, obviamente, à manufatura literária desenvolvida a partir do novo milênio -, outrora o mote sobre vampiros também se presentificara no curso da história literária. Anne Rice, autora de As crônicas vampirescas (Rocco, 1976), e L. J. Smith, responsável pela série Diários do vampiro (Galera Record, 2009) - originalmente publicada em 1991 -, são alguns exemplos de escritoras as quais já haviam se aventurado por este universo. Remetendo-nos a temporalidades ainda mais pretéritas, se figuraria expressivo equívoco nos olvidarmos do conto The Vampyre, de John William Polidori, responsável por expandir, há aproximadamente duzentos anos, as possibilidades de escrita sobre o tema em destaque - o escritor é reconhecido como um dos precursores quanto às produções deste gênero, tendo sido influenciado por algumas das produções escritas da autoria de Lord Byron.

6 Traduzido no Brasil como Buffy, a Caça-Vampiros. 
Moretti (2008) nos explica que os ciclos se iniciam caso as formas precedentes já tenham praticamente se esgotado. Em alguns casos, segundo o pesquisador, longas décadas de espera se fazem necessárias, "[...] provavelmente porque enquanto uma forma hegemônica não perdeu o seu valor artístico, as formas rivais não têm muitas cartas para jogar [...]" (2008, p.32 - grifo do autor). Claramente, é possível que algum evento excepcional ocorra como os booms de A menina que roubava livros (Intrínseca, 2007) ou A cabana (Sextante, 2008) -, mas é certo que estas exceções dificilmente deterão força e poder suficientes para transformar por completo o sistema em constância.

Comprovando a veracidade deste fato, aqui nos recordamos que já em meados do ano de 2010 fizeram-se perceptiveis os distintos lançamentos literários ainda atrelados à temática sobrenatural, embora com a presença de outras criaturas misteriosas como protagonistas, os anjos. Seres humanos e celestes protagonizavam histórias cujos enredos se desenvolviam em atmosfera apocalíptica e obscura, em meio à guerra entre céu e terra. As obras foram cativas ao público jovem, o qual pudera selecionar entre diversos títulos, desde os livros da série escrita por Lauren Kate, Fallen (Record, 2010); aqueles pertencentes à quadrologia da autoria de Becca Fitzpatrick, Hush, hush (Intrínseca, 2011); e a coleção de seis volumes, Fallen angels (Universo dos Livros, 2011), assinada por J. R. Ward.

O momento histórico também corresponde a elemento capaz de influenciar a dinâmica literária7. Para Moretti (2008, p.41),

7 Não nos olvidemos do massivo lançamento de obras literárias impressas resultantes da dinâmica de investimento literário na materialidade do conteúdo digital produzido por jovens celebridades e influenciadores digitais, em sua maioria, blogueiros e youtubers. 
quando específico gênero vem a substituir outro em particular, tendo isto ocorrido em determinada passagem histórica, podemos refletir quanto ao fato de que tal mutação acontece apenas por razões históricas e internas aos gêneros em questão. Afinal, "[...] coletâneas de cartas de amor têm muito menos sintonia com uma época revolucionária do que dramas sanguinários de vítimas inocentes e senhores cruéis [...]" (MORETTI, 2008, p.41). Embora haja sentido nesta assertiva, o excerto nos conduz a pensar em movimento contrário, no qual a Literatura se figura aquela responsável por ditar modismos de uma época - sobretudo no próprio campo de manifestação literária. Esta hipótese, então, se constitui detentora de maior fidedignidade, uma vez que quando a obra de Mayer fora publicada, não havia claros indícios de que a predileção pela abordagem de criaturas sobrenaturais e misteriosas, como os vampiros, se constituiria, talvez, uma forte tendência naquele momento. Retomando passagens anteriores do presente artigo, reiteramos o surgimento, em uma mesma época, de inúmeros títulos literários cujas temáticas e cujos elementos narrativos se assemelham entre si.

A densidade do fenômeno Crepúsculo (2008) se reverbera nesta atualidade. Aproximadamente dez anos se passaram desde a publicação do primeiro livro da saga, mas, ainda assim, os debates sobre as personagens, as histórias dos habitantes da cidade de Forks ou os vampiros dos clãs Cullen e Volturi se fazem presentes em fóruns online de discussão, rodas de conversa, diálogos em clubes literários, resenhas divulgadas em blogs ou canais do YouTube e fanfics compartilhadas em plataformas virtuais de redação e autopublicação literária, como Spirit Fanfics ou Wattpad. Portanto, entendemos que 
Twilight sobrevive em meio ao lançamento de tantas outras obras relativas à Literatura de viés sobrenatural, podendo ser considerada como responsável, na atual contemporaneidade, por viabilizar caminhos - relativos à escrita e, acima de tudo, mercadológicos - aos autores iniciantes e, por que não, já estabelecidos, que objetivem trazer à luz temas similares.

A obra de Stephanie Mayer se constitui latente no inconsciente coletivo de ávidos consumidores da Literatura Contemporânea. Crepúsculo (2008) é o best-seller de uma geração de jovens, muitos dos quais foram apresentados à prática da leitura a partir de tal obra e, por conseguinte, lograram imergir no universo literário graças ao seu enredo. Os leitores da saga vampiresca ainda continuam em cena e, por esta razão, mantém seus livros vivos, transformando-os em objetos passíveis de atenção, comercialização e consumo.

Categorizado como produto concernente à Literatura de Entretenimento, Twilight alcançou em poucos meses as primeiras posições como livro impresso mais vendido no ano no qual fora lançado em território nacional, em meados de 2008. O sucesso de vendas alcançado por esta obra corresponde a algo indiscutível. Embora seja verdade, ainda hoje "[...] os best-sellers são uma classe de livros [...] menosprezada como sendo composta de objetos de diversão e não estudados como trabalhos de arte literária ou, no mínimo, como trabalho artístico considerável [...]" (ACHER \& JOCKERS, 2017, s/p). Assim preconizam Jodie Archer e Matthew Jockers, estudiosos e autores de $O$ segredo do bestseller: tudo o que você precisa saber para escrever um livro campeão de vendas (2017). 
Muitas minúcias se perdem ao nos desfazermos das possibilidades de análises de fenômenos literários como Crepúsculo (2008), especialmente no que diz respeito à cultura contemporânea, conforme apontam Acher e Jockers (2017). Isto, pois a dinâmica social de consumo e mercado encontra-se fortemente atrelada às relações de cunho cultural.

Embasando-nos nas ponderações de Acher e Jockers (2017, $\mathrm{s} / \mathrm{p})$ em relação àquilo que seus estudos apontam como sendo características proeminentes de livros considerados best-sellers, logo nos tornamos capazes de entender por que a coleção literária de Stephanie Mayer experimentara boom de vendas, crítica e recepção quando lançada ao mercado. Segundo os autores, conflitos movem os enredos apresentados por livros, o que corresponde a aspecto de considerável importância para que uma produção literária venha a se tornar sucesso de adesão e comercialização entre os leitores. De fato, a cada volume da saga podemos acompanhar as problemáticas enfrentadas pelas personagens, as quais se alternam entre os livros, dividem a atuação junto a outras, ou ainda, concedem espaço para que novos protagonistas, coadjuvantes e vilões venham também a ganhar o devido destaque no decorrer da trama literária, tornandose, estes, imprescindíveis à narrativa.

De acordo com Acher e Jockers (2017, s/p), gêneros e temas não se constituem unicamente fatores de relevância para que um livro alcance as melhores posições da lista de mais vendidos. Este tópico nos permite refletir quanto ao fato de que se Twilight trouxesse à tona atmosfera outra, distinta daquela preconizada por Mayer, com outras criaturas ou cenários, por exemplo, sem embargo a história de Edward e Bella poderia deter, se 
não o mesmo, sucesso muito próximo àquele originalmente conquistado $^{8}$. A explicação mais provável a esta possibilidade se encontra na combinação entre fatores, a qual, assim ressaltam os estudiosos, é indispensável à fama de um livro - dentre estes, alguns presentes em Crepúsculo (2008), como a abordagem de ameaças e relações de afeto e intimidade.

Por fim, um livro tido como best-seller não necessariamente corresponde a uma obra de boa qualidade, pontuam Acher e Jockers (2017, s/p), o que não nos surpreende, haja vista que o valor de literariedade não se constitui fator comumente relevante à expressiva parcela de indivíduos a qual irá adquirir este ou aquele livro. Segundo os teóricos, o que na realidade os leitores procuram ao se deleitar por uma obra literária são os reflexos de suas facetas nas personagens apresentadas pelo enredo, além de experienciar emoções diversas, muitas das vezes até então jamais plenamente vivenciadas.

Decorre daí, talvez, a razão que há por detrás da adesão à obra por contingente majoritariamente constituído por jovens indivíduos. Afinal, é exatamente na fase vital relativa à juventude que "[...] as leituras abrem para um novo horizonte e tempos de devaneio que permitem a construção de um mundo interior, um espaço psíquico [...]" (PETIT, 2009, p.32), de acordo com Michèlle Petit, estudiosa à frente da produção teórica $A$ arte de ler: ou como resistir à adversidade (2009). Dificilmente um adolescente, ainda que nascido em continente distinto ou época remota, garota ou garoto, não se identificaria com os impasses familiares, sociais e escolares

8 Contudo, fora devido à abordagem do tema vinculado ao universo vampiresco que esta vertente literária ganhara força e espaço no mercado nos anos 2000. 
que perpassam o romance vivido por Edward e Bella - daí o fato de que tanto o livro quanto o filme lograram sucesso em inúmeros países. Este sentimento universal, o qual conecta milhares de jovens leitores espalhados ao redor do mundo, também se presentifica no cerne do debate sobre o contato destes indivíduos com títulos literários manufaturados em meio à liquidez contemporânea.

A obra A literatura em perigo (2010), cujo autor é o filósofo Tzvetan Todorov, nos expõe à reflexão de questões atinentes à Literatura, concebendo-a como algo mais que "[...] um simples entretenimento, uma distração reservada às pessoas educadas [...]" (TODOROV, 2010, p.23). Para o autor, a manifestação literária permite que cada indivíduo venha a se tornar capaz de melhor responder aos seus potenciais e às suas vocações enquanto seres humanos. $E$ acresce, adiante: "[...] a literatura amplia o nosso universo, incitanos a imaginar outras maneiras de [...] organizá-lo [...]" (TODOROV, 2010, p.23). Embora nos apresente a estas prerrogativas, Todorov (2010, p.24) elenca algumas das inconsistências relativas ao trabalho escolar no campo literário, os quais influenciam diretamente o processo de formação de jovens leitores. Afinal, o contato de aprendizes com a Literatura frequentemente acontece via tópicos de discussões que auxiliam a compreensão, de modo demasiado generalista, da língua mãe em questão.

Logo, entendemos que o famigerado perigo ao qual Todorov (2010, p.9) se refere, inclusive, no título de sua obra, se encontra no fato de que os estudantes não contatam a Literatura mediante a leitura de textos literários, “[...] mas alguma forma de crítica, de teoria ou de história literária [...]" (2010, p.10). O acesso a esta manifestação artística, portanto, ocorre de modo disciplinar 
e institucional, imbuído das tradições há tempos cultivadas e largamente disseminadas no ambiente propiciador do saber.

A despeito dos esforços empreendidos no transcorrer dos últimos anos, observamos a fuga de jovens alunos em relação à Literatura que lhes é imposta nas escolas, sendo - para o desespero de tais instituições - muito bem recepcionados e acolhidos por aquilo que o ensaísta Mario Vargas Llosa (2013, p.31) outrora adjetivou, em clara menção às ficções literárias de viés estritamente comercial, como Literatura light, leve e ligeira.

Contra as expectativas das autoridades escolares, Todorov (2010, p.82) encoraja a leitura de romances como Os Três Mosqueteiros e Harry Potter - aqueles, de acordo com o estudioso, os quais foram considerados com condescendência ou desprezo por críticos e profissionais vinculados ao ramo literário. Talvez a passagem de maior importância presente no posicionamento de Todorov (2010) se refira ao ponto no qual o filósofo reconhece que o acesso a estes livros populares conduziu muitos jovens ao hábito da leitura e também Ihes possibilitou a construção de perspectivas sobre o mundo, cujas "[...] leituras posteriores se encarregarão de tornar mais complexas e nuançadas [...]" (TODOROV, 2010, p.82). Esta citação embasa nosso argumento de que o debate não possui como enfoque a substituição de títulos canônicos por best-sellers no contexto do processo de formação de leitores. Relaciona-se, na realidade, à compreensão de que estes são capazes de atuar como molas propulsoras a outras futuras leituras e Literaturas. Afinal, tal como esclarecido por Peter Hunt em Crítica, teoria e literatura infantil (2010), não sugerimos o início de um movimento anárquico educacional - pautando-nos aqui nos próprios termos utilizados 
pelo autor. Ao apresentarmos ao indivíduo um livro categorizado como clássico, devemos também deixar claro que não há nada intrinsecamente melhor no texto em questão.

Obras contemporâneas aos jovens aos quais aqui nos referimos vieram a se tornar grandes cânones de suas gerações, detentores, cada qual, de específicas singularidades atreladas aos comuns elementos da narrativa literária, entre enredo e personagens, responsáveis, de algum modo, por fazer com que se deleitassem por entre as inúmeras viabilidades da Literatura. Em Leituras: do espaço íntimo ao espaço público (2013), novamente Michèlle Petit, adequadamente embasada a partir da realização de estudos e pesquisas concernentes à sua área de atuação, confirma-nos: "[...] evidentemente, os adolescentes pedem por determinado bestseller e gritam contra qualquer texto que se afasta dos caminhos trilhados [...]" (2013, p.48, grifo da autora). Enganam-se aqueles que creem se configurar tal atitude algo prejudicial. Isto, pois a prática da leitura nesta fase vital possui caráter eclético, já que "[...] os adolescentes aproveitam tudo o que cai em suas mãos, sem pensar em classificações determinadas [...]" (PETIT, 2013, p.48).

Diante disto, o mercado editorial apropria-se de movimentos vários capazes de explorar tal interesse, resultando ainda na realização de outro movimento de igual relevância por parte das diversas mídias modernas - todas cientes de que a prática de leitura não mais deve ser concebida isoladamente e que a nova geração de jovens é capaz de, sozinha, definir e estabelecer os critérios para eleger seus próprios clássicos. 


\section{DE FENÔMENO LITERÁRIO A PRODUTO DA CONVERGÊNCIA MIDIÁTICA}

Certamente, o universo de seres sobrenaturais jamais estivera em evidência tal como ocorrera quando presenciamos o despontar referente ao lançamento do primeiro volume constituinte de The Twilight Saga, promovido em território norte-americano em meados do ano de 2005. Responsável por abordar, dentre outras questões, também acerca das peculiaridades inerentes à classe dos vampiros, Crepúsculo, lançado pela editora Intrínseca em solo nacional apenas três anos mais tarde, viera a desmistificar comuns e pregressos estereótipos de que estas criaturas, presentes no imaginário folclórico e popular, são avessas a elementos como luz e crucifixos, ou que se constituem sedentas, única e exclusivamente, por se alimentar de sangue humano - mas apenas por tais mencionados aspectos.

Os vampiros idealizados por Stephanie Mayer brilham como diamantes quando se expõem à luz solar, bem como em momento algum parecem temer o contato com objetos sagrados. E Edward Cullen, o protagonista vampiro da série, declara todo o seu atemporal e místico amor por uma adolescente humana chamada Isabella Swan - carinhosamente apelidada por amigos e familiares como Bella. O vampiro, anti-herói engendrado com base em clássicos moldes byronianos ${ }^{9}$, é inteligente - perdemos as contas de quantas vezes cursou o Ensino Médio, visto sua centenária existência de dezessete anos de idade -, introspectivo - frustradas são as tentativas de adentrar a mente de Bella - e sedutor - sua aura

9 Esta terminologia alude às personagens retratadas nas obras de Lord Byron (1788 - 1824), influente escritor e poeta britânico atuante durante a fase do Romantismo. 
de frieza e indiferença é responsável por atrair algumas garotas da escola. Além disto, é de origem aristocrática. O estabelecimento de relacionamento amoroso entre ambos os jovens obviamente enfrenta alguns entraves, dentre os mais notáveis, a dificuldade de aceitação por membros da família do casal ou a inquietante desconfiança dos integrantes do tradicional clã dos vampiros Volturi, o que os conduz, ao final, a uma épica batalha.

Cabe ressaltarmos, ainda, a existência de personagens sem as quais o curso da história de amor protagonizada por Edward e Bella não seria o mesmo. Jacob, amigo da garota, descobre-se lobisomem no segundo título da quadrologia, Lua nova (2008). Victoria, por seu turno, apresenta-se proeminente em Eclipse (2009), terceira obra da saga, perseguindo Bella em uma tentativa de extermínio que se apresenta, em seu término, completamente ineficaz. É preciso nos recordarmos, a tempo, da atuação da filha de Edward e Bella, de nome Renesmee, que enquanto espécie de ser de natureza híbrida, fizera-se imprescindível ao inesperado desfecho da história em Amanhecer (2009).

Stephanie Mayer também se aventurara no processo de escrita de outros livros, para além da saga que a elevou a patamares os quais dificilmente um escritor iniciante alcançaria em circunstâncias normais. A exemplo disto, é possível mencionarmos os títulos literários A mediadora (2009) ${ }^{10}$ e A química (2016), ambos lançados no Brasil também pela editora Intrínseca. Reconhecemos que estas obras obtiveram considerável sucesso, contudo, não tanto quanto aquele que seus editores e produtores almejavam lograr não exclusivamente devido a este fato, mas parcialmente por ter 10 À época de sua comercialização, tal obra fora adaptada para as telas do cinema. 
sido sua autora aquela responsável pela concepção do universo vampiresco e sobrenatural referente à Crepúsculo (2008).

Tal acontecimento não acometera apenas a carreira de Mayer. Ao depositarmos atentos olhares à expressão literária produzida a nível mundial, nos tornamos capazes de averiguar que célebres escritores, perpassando por J. K. Rowling e Rick Riordan, respectivamente autores das coleções Harry Potter (Rocco, 2000) e Percy Jackson (Intrínseca, 2010), também se arriscaram a atuar em searas literárias outras e não alçaram voos tão altos ou longínquos como executaram a partir de seus primordiais e memoráveis lançamentos no mercado, decerto responsáveis por fixar, por semanas ininterruptas, seus nomes nos topos das listas de livros impressos mais vendidos ao redor de todo o mundo ${ }^{11}$-fato que corrobora com a teoria de Moretti (2008) já apresentada, a julgar que estes autores arriscaram lançamentos literários externos aos temas cultuados em seus primeiros ciclos.

Em comemoração ao aniversário de dez anos a contar a data de lançamento de Crepúsculo (2008), Stephanie Mayer lançara Vida e morte: crepúsculo reimaginado (Intrínseca, 2018) - no exterior a obra fora comercializada no ano de 2015, chegando ao Brasil apenas em 2018. Trata-se de uma espécie de releitura do livro o qual dera início à trajetória percorrida por seres humanos, vampiros e lobisomens, apresentando-nos à inversão de gêneros entre as personagens Beaufort Swan e Edithy Cullen. A autora também desenvolveu projeto no qual a história de Crepúsculo (2008) é narrada sob a perspectiva do vampiro Edward Cullen, a qual seria

11 Em relação à autora J. K. Rowling, citamos o título Morte súbita (Nova Fronteira, 2012). Referente ao escritor Rick Riordan, podemos mencionar a série Tres navarre (Record, 2011). 
publicada sob o título Midnight sun ${ }^{12}$. Todavia, após o vazamento dos primeiros capítulos da obra no meio virtual, Mayer optou por estagnar sua escrita e disponibilizá-la aos apreciadores da saga apenas em seu website oficial.

Defronte a este panorama o qual gradualmente se delineou frente às melhores expectativas cultivadas por fãs de Twilight, - fenômeno literário de Crepúsculo (2008) experimentara seu ápice não apenas no momento de lançamento do primeiro filme, mas certamente, e sobretudo, a partir da distribuição de títulos sobressalentes à série, tais como $A$ breve segunda vida de Bree Tanner (2010); livros relativos ao universo cinematográfico propiciado pelo enredo, entre estes, Crepúsculo: livro de anotações da diretora (2009) e Crepúsculo: guia oficial ilustrado da série (2011); ou ainda, a apresentação da narrativa sob diferentes modalidades, como é o caso de Crepúsculo: graphic novel (2011), com ilustrações inspiradas nos moldes dos mangás japoneses, sendo lançado em dois volumes.

Também houvera o lançamento de outros títulos literários atrelados à atmosfera vampiresca, no entanto, produzidos ou organizados por outros autores e publicados por outras editoras. Trazemos ao conhecimento obras tais como Crepúsculo e a filosofia: vampiros, vegetarianos e a busca pela imortalidade (Madras, 2010); Stephanie Mayer: a biografia não autorizada da criadora da saga Crepúsculo (Jardim dos Livros, 2010); Vampiros além da saga Crepúsculo: tudo o que você precisa saber sobre os vampiros e Stephanie Mayer não contou em seus romances (Pensamento, 2010); Mordida de amor: o guia não oficial da saga Crepúsculo

12 Do inglês, tradução nossa: Sol da meia-noite. 
(Rai, 2011); entre incontáveis outros. Tais publicações destacam que em torno de um ciclo na Literatura, vários gêneros e nichos são impelidos a se movimentar e, por conseguinte, explorar as temáticas que se encontram em evidência.

Toda esta potencial e singular dinâmica viera a tornar o universo de Twilight talvez a mais aclamada e rentável franquia literária desde a saga britânica Harry Potter (Rocco, 2000), a qual abordou, semelhante à Crepúsculo (2008), atmosfera fantástica na qual seres humanos e mágicos se encontram, ganham vida e escrevem suas próprias histórias, saltando das páginas impressas dos livros para as telas dos cinemas, dos televisores, dos computadores e demais dispositivos eletrônicos. Aliás, atualmente a Literatura se constitui, sobrevive e se transfigura para além do tradicional e até então exclusivo suporte impresso.

A respeito deste específico tópico de discussão, o estudioso Henry Jenkins, autor da obra Cultura da convergência (2008), nos relata que este movimento de convergência contempla transformações as quais são experienciadas pelos modos de produção e, como consequência, também pela maneira por intermédio da qual consumimos as informações a nós cotidianamente apresentadas. Em meio a esta inovadora dinâmica, especialmente de cunho mercadológico, remotas, recentes, alternativas e coorporativas mídias, encontram-se e deleitam-se. Como resultado de suas colisões, cruzamentos e diálogos, conforme assim podemos acrescer, sob a perspectiva do pesquisador, "[...] o poder do produtor de mídia e o poder do consumidor interagem de maneiras imprevisíveis [...]" (JENKINS, 2008, p.30). 
Quanto a isto, Cultura da conexão (2015), da autoria do mesmo teórico, nos apresenta a interessante situação experienciada por produtores e fãs da saga em voga. Durante a edição final do filme Amanhecer - Parte I, houvera o vazamento de algumas imagens na Internet. Diante deste acontecimento, Summit Entertainment, produtora responsável pela adaptação cinematográfica, apelou aos admiradores da franquia que não visualizassem tais fragmentos e não os compartilhassem, a fim de que esta ação infratora deixasse de deter ainda mais força. Jenkins $(2015, \mathrm{~s} / \mathrm{p})$ relata que muitos fãs cooperaram e, por este motivo, reduziram a propagação não autorizada dos vídeos. Ocorrências tais como esta nos conscientiza quanto ao fato de que o formato do sistema cultural em vigência ainda se encontra em fase de transição e extrema fragilidade. Portanto, batalhas coletivas para que haja a definição de ambiente midiático mais ético se fazem pertinentes à atual indústria do entretenimento. Ora, a própria interrupção da escrita de Midnight sun por parte de Stephanie Mayer ratifica tal hipótese, já que a recepção do público pode ter sido, paralelamente, um dos vetores para a sua decisão de manter a obra apenas no ciberespaço.

Atualmente, autores e leitores, ídolos e fãs, interagem e partilham impressões com o auxílio das ferramentas ofertadas por populares redes sociais e plataformas virtuais, como Facebook, Instagram e Twitter. O estabelecimento de diálogos e relacionamentos entre ambas as partes tornara-se algo viável a partir da diária expansão da grande rede de computadores. Se antes expressar admiração por esta ou aquela eloquente personalidade se fazia possível apenas por meio do envio de cartas ou da participação em concursos televisivos, hoje a conexão de fibra 
óptica viabiliza a criação e o estreitamento de laços de amizade, companheirismo e trabalho entre os envolvidos. No contexto de interação virtual encabeçada por fãs de Twilight, é possível mencionarmos a existência de algumas populares comunidades online nas quais entretenimentos diversos são ofertados aos apreciadores; são algumas delas: Foforks, Twilight Brasil, Twilight Moms e Twilighters.

Contágio: por que as coisas pegam (2014), de Jonah Berger, disserta-nos a respeito da relevância do advento das novas tecnologias digitais, enfatizando de que modo o espaço virtual tornara-se responsável pelo impulso relativo à disseminação dos conteúdos em diferentes continentes e para inúmeros indivíduos - "[...] essas tecnologias tornaram mais fácil [...] compartilhar coisas rapidamente com um amplo grupo de pessoas [...]" (BERGER, 2014, p.12). Em consonância a estes preceitos, o autor de Como viver na era digital (2012), Tom Chatfield, posicionase a respeito do espaço de diálogo e interação promovido pela Internet e suas facetas várias, salientando ser este "[...] uma passagem para o lugar onde lazer e trabalhos estão interligados [...]" (CHATFIELD, 2012, p.9).

Influenciadas pela rede cibernética a qual se transfigura em torno de todos os seus navegantes, as empresas atreladas à comercialização de mídias e marcas passam então a se preocupar com a face econômica oriunda da economia afetiva, para além, unicamente, da qualidade das experiências ofertadas. De acordo com Jenkins (2008, p.97), tal ramificação, proveniente do campo de estudos do Marketing, enaltece a necessidade no que se refere à quantificação do desejo, à mensuração das relações e à 
transformação da interação afetiva em commodities. O sentimento transfigura-se, portanto, produto vendável.

Imersos no fenômeno Twilight e devidamente embasados pelo aporte teórico anteriormente elencado, somos capazes de aqui nos recordar dos empreendimentos multimidiáticos - e extremamente rentáveis, diga-se de passagem - vinculados à franquia em destaque, entre estes, a criação de games virtuais não oficiais, encabeçada por admiradores da saga; a composição de faixas musicais exclusivas para o filme, bem como a organização de trilhas sonoras em formato físico e digital; a comercialização de brinquedos e produtos de uso pessoal, tais como vestimentas e artigos congêneres ou objetos para fins decorativos; e, por fim, álbuns de figurinhas, guias e manuais exclusivos, edições especiais de revistas teen, cards colecionáveis e outros materiais expostos em bancas.

Inclinando-se sobre o campo de manifestação literária, Jenkins (2008) acredita que os jovens consumidores, frente à significativa quantidade de produtos os quais se originam de suas obras prediletas, transformam-se em verdadeiros "[...] caçadores e coletores de informações [...]" (JENKINS, 2008, p.169). Expressam inabalável prazer em rastrear os antecedentes relativos às personagens que compõem os enredos literários os quais admiram, ou ainda, às específicas passagens da história em questão, propiciando-Ihes, consequentemente, a realização de conexões entre distintos textos constituintes de uma única franquia. Logo, são idealizadas novas narrativas, as quais concedem trajetórias inimagináveis e diversas aos protagonistas, coadjuvantes, vilões e outras personagens. 
Exemplificamos este fato ao nos reportarmos à elaboração e à partilha de fanfics no ciberespaço. A partir das exaustivas práticas de escrita no ambiente eletrônico, anônimos internautas se aventuram e se divertem como autores de suas próprias histórias, tomando de empréstimo os heróis os quais Ihes fora oportunizado conhecer outrora somente no decorrer das páginas dos livros impressos. Alguns encaram como ocupação profissional, e caso obtenham sucesso na Web, têm seus livros publicados por grandes grupos editoriais ${ }^{13}$.

Entretanto, há jovens escritores os quais não obtiveram acesso a plataformas virtuais de redação e publicação literária, mas ainda sim lograram alcançar expressiva fama a partir daquilo que até então consideravam como esboço de provável bestseller. Como quase namorei Robert Pattinson (Jangada, 2011), de autoria da jovem blogueira Carol Sabar, apresenta-nos à história da adolescente Duda, fã da saga Twilight e que por acaso mantém perfil fake na Internet, por meio do qual se comunica com outros admiradores do universo em voga. Este é o ponto de partida para que as divertidas aventuras da personagem Duda se desenvolvam tendo como foco sua inabalável paixão pelo vampiro Edward Cullen, originário de Crepúsculo (2008) e interpretado no cinema pelo ator Robert Pattinson.

Os frios, úmidos e temidos bosques da cidade norte-americana de Forks, liricamente descritos por Stephanie Mayer em suas obras,

13 A escritora norte-americana E. L. James, autora da trilogia Cinquenta tons de cinza (2011), declarou, em entrevista ao website Estadão, ter sido Crepúsculo (2008) a inspiração para a escrita de suas obras de conteúdo erótico, consideradas best-sellers desta contemporaneidade. Para o acesso a mais informações, sugerimos o seguinte link: https://cultura.estadao.com.br/noticias/literatura,autora-de-cinquenta-tons-de-cinzafala-de-sua-inspiracao-para-criar-o-best-seller,931143 Acesso em 15.Mar.2019. 
foram cenários efetivamente capazes de nos demonstrar que The Twilight Saga mobilizou não somente o mercado de consumo de produtos ou livros impressos, mas de dinamizar, junto a outras importantes obras literárias, de faceta sobrenatural ou não, a interação entre jovens fãs, pretensos a se tornarem promissores escritores e leitores de suas gerações, influenciando positivamente seus pares.

\section{CONSIDERAÇÕES FINAIS}

Talvez o maior legado atinente à saga Crepúsculo (2008) possa ser averiguado ao depositarmos atentos olhares à formação de novos leitores. Desvendados alguns mistérios e sustentáculos relativos ao estrondoso sucesso literário e multimidiático de The Twilight Saga, obtemos embasamento adequado para que possamos refletir sobre o quão relevante se fizeram - e ainda o fazem - estes livros à história da Literatura Juvenil Contemporânea.

Reportando-nos a anteriores passagens, de fato se figura louvável a fama alcançada pelo enredo sobrenatural por intermédio do qual Edward e Bella amadurecem e lutam contra seus próprios medos e incertezas. Em parte banal, tendendo quase ao clichê, este fenômeno literário ressignificou o modo de se produzir, comercializar e refletir a Literatura dedicada ao público jovem, protagonista da atual modernidade. Há dez anos, quando as novas tecnologias ainda caminhavam a sutis e a tímidos passos, Crepúsculo (2008) desde já nos demonstrara sua promissora singularidade diante das viabilidades de se constituir para além de comum produção literária, em temporalidade na qual likes, hashtags e shares ainda não se faziam elementos conhecidos - ou quiçá discutidos em contexto digital. 
Jovens indivíduos encontraram a si próprios e a Literatura a partir de suas imersões por entre as deslumbrantes vegetações dos bosques localizados em Forks ou os campos utilizados como cenários para as épicas batalhas travadas entre seres humanos, vampiros e lobisomens. E estes mesmos jovens também encontraram pares com os quais debater acerca dos poderes desenvolvidos por cada membro da família Cullen ou como poderia ter sido a vida de Bella caso esta escolhesse permanecer distante de Edward, junto a Jacob.

Ainda romantizada, a figura do vampiro moderno, representada na coleção literária por Edward Cullen, seus familiares e seus inimigos, se delineia com base no arquétipo remotamente trazido à luz por Lord Byron - com exceção de que tais seres, na obra de Stephanie Mayer, dirigem Jeeps, Porshes e Volvos blindados e de última geração e ostentam os melhores e mais onerosos aparelhos celulares e relógios de pulso. Não tarde, é preciso evidenciar que Cullen e seus irmãos são estudantes colegiais, cursam Matemática, possuem parceiros de laboratório, preocupam-se com exames e conceitos avaliativos e almoçam diariamente no refeitório de sua escola, segmentados e categorizados em grupos por suas aptidões ou estilos de vida. Portanto, se por um lado o protagonista vampiro em muitas questões se distancia de comuns jovens de quinze ou vinte anos idade, leitores de sua história, em aspectos outros se aproxima e compartilha de êxitos e insucessos enquanto adolescente e estudante por aproximadamente cento e dezessete anos de idade.

A construção destas personagens vampirescas, talvez por não nos apresentar significativas novidades em relação ao modelo historicamente atrelado aos seres de natureza sobrenatural, presentes na Literatura, possibilitou o depósito de perspectivas distintas a este 
nicho literário. Tradicionalmente, afinal, as criaturas em destaque, além de se constituírem vinculadas à atmosfera byroniana, desde sempre estiveram envoltas por corriqueiros enredos demasiado obscuros sem chance alguma para o amanhecer, em vias contrárias à proposta de Mayer. Claramente, The Twilight Saga não ignora a modernidade comum à temporalidade na qual a história se desenvolve, embora verifiquemos a existência de importantes flashbacks históricos dedicados ao caminhar de alguns de seus vampiros.

No que se refere à prática de leitura por jovens indivíduos, decerto, o contato com os produtos literários provenientes de seus próprios tempos, similar àquilo que ocorre com Crepúsculo (2008), será capaz de tornar mais sofisticadas suas experiências frente às habituais exigências pertinentes, em geral, ao currículo escolar e à trajetória vital.

Logo, representantes da identidade cultural do zeitgeist ${ }^{14}$ ou das circunstâncias as quais se encontra sujeita a dinâmica do mercado de consumo, os vampiros ficcionais desta contemporaneidade, seres resultantes da peculiar hibridez característica de tempos líquidos e modernos, interceptados por antigas e novas tecnologias, de líderes de temidos e tradicionais clãs a estudantes colegiais, de Lord Ruthven ${ }^{15}$ a Edward Cullen, também reivindicam um lugar ao sol - ou não; ou apenas espaços nas prateleiras de livros ou nos fóruns de discussão online sediados no ciberespaço - e os têm logrado com êxito.

14 Termo de origem alemã o qual diz respeito ao clima cultural e intelectual a nível mundial. 15 Lord Ruthven é tido como o primeiro vampiro presente na Literatura, podendo ser melhor conhecido a partir da leitura do conto The Vampyre (1819), da autoria de John William Polidori. 


\section{REFERÊNCIAS}

ACHER, Jodie; JOCKERS, Matthew L. (2017). O segredo do best-seller: tudo o quê você precisa saber para escrever um livro campeão de vendas. São Paulo: Astral Cultural. BERGER, Jonah (2014). Contágio: por que as coisas pegam. Rio de Janeiro: Leya. CABOT, Meg (2011). Insaciável. Rio de Janeiro: Record.

CAST, P.C. (2007). House of night. São Paulo: Novo Século.

CHATFIELD, Tom (2012). Como viver na era digital. São Paulo: Objetiva.

CLAIRE, Cassandra (2013). Os instrumentos mortais. Rio de Janeiro: Record.

DUNN-MASCETTI, Manuela (2010). Vampiros além da saga Crepúsculo: tudo o que você precisa saber sobre os vampiros e Stephanie Mayer não contou em seus romances. São Paulo: Pensamento.

HARDWICKE, Catherine (2009). Crepúsculo: livro de anotações da diretora. Rio de Janeiro: Intrínseca.

HOUSEL, Rebecca; WISNEWSKI, J. Jeremy (2010). Crepúsculo e a filosofia: vampiros, vegetarianos e a busca pela imortalidade. São Paulo: Madras Editora. HUNT, Peter (2010). Crítica, teoria e literatura infantil. São Paulo: Cosac Naify. FITZPATRICK, Becca (2011). Hush, hush. Rio de Janeiro: Intrínseca. HARRIS, Charlaine (2009). Morto até o anoitecer. São Paulo: Ediouro. HAUCK, Colleen (2011). A maldição do tigre. São Paulo: Arqueiro. JAMES, E. L (2011). Cinquenta tons de cinza. Rio de Janeiro: Intrínseca. JENKINS, Henry (2011). Cultura da convergência. São Paulo: Aleph. (2015). Cultura da conexão. São Paulo: Aleph.

KATE, Lauren (2010). Fallen. Rio de Janeiro: Record.

LLOSA, Mario Vargas (2013). A civilização do espetáculo: uma radiografia do nosso tempo e da nossa cultura. São Paulo: Objetiva.

MAYER, Stephanie (2008). Crepúsculo. Rio de Janeiro: Intrínseca. (2008). Lua nova. Rio de Janeiro: Intrínseca. (2009). Eclipse. Rio de Janeiro: Intrínseca. (2009). Amanhecer. Rio de Janeiro: Intrínseca. 
(2009). A mediadora. Rio de Janeiro: Intrínseca. (2010). A breve segunda vida de Bree Tanner. Rio de Janeiro: Intrínseca. (2011). Crepúsculo: graphic novel. Rio de Janeiro: Intrínseca. (2011). Crepúsculo: guia oficial ilustrado da série. Rio de Janeiro, Intrínseca. (2016). A química. Rio de Janeiro: Intrínseca.

(2018). Vida e morte: crepúsculo reimaginado. Rio de Janeiro: Intrínseca. MARION, Isaac (2012). Sangue quente. Rio de Janeiro: Leya. MEAD, Richelle (2007). Academia de vampiros. São Paulo: Agir. MORETTI, Franco (2008). A literatura vista de longe. Porto Alegre: Arquipélago Editorial.

PETIT, Michèlle (2009). A arte de ler: ou como resistir à adversidade. Porto Alegre: Editora 34.

(2013). Leituras: do espaço íntimo ao espaço público. Porto Alegre: Editora 34.

RICE, Anne (1976). Crônicas vampirescas. Rio de Janeiro: Rocco. RIODAN, Rick (2010). Percy Jackson. Rio de Janeiro, Intrínseca. (2011). Tres navarre. Rio de Janeiro: Intrínseca.

ROWLING, J. K (2000). Harry Potter. Rio de Janeiro: Rocco. (2012). Morte súbita. Rio de Janeiro: Nova Fronteira.

SABAR, Carol (2011). Como quase namorei Robert Pattinson. São Paulo: Jangada. SHAPIRO, Marc (2010). Stephanie Mayer: a biografia não autorizada da criadora da saga Crepúsculo. São Paulo: Jardim dos Livros.

SMITH, L. J (2009). Diários do vampiro. Rio de Janeiro: Record.

SPENCER, Liv (2011). Mordida de amor: o guia não oficial da saga Crepúsculo. São Paulo: Rai Editora.

TODOROV, Tzvetan (2010). A literatura em perigo. Rio de Janeiro: Difel.

WARD, J. R (2011). Fallen angels. São Paulo: Universo dos Livros.

YOUNG, William P (2008). A cabana. Rio de Janeiro: Sextante. 